\title{
EDITORIAL
}

\section{Remember the Noosphere}

$\mathrm{O}$ ne of the realizations which never ceases to surprise us whenever we think of it -as we are practically forced to do with increasing frequency as one after another calamity threatens our world-is that, although our pandominant species now has the knowledge and capacity to save itself and much of what remains of Nature for posterity, it makes no really concerted effort to do so. Yet the germ and very basis of solution could lie in the noosphere, which seems to its more enthusiastic advocates to include Mankind's capability of so organizing itself as to satisfy The Biosphere's basic problems, such as human overpopulation and profligacy. Clearly we could also get rid of such very grave threats as those of further extensive desertification, terminal deforestation, and nuclear holocaust-in the last instance finally.

The noosphere (from the Greek noos, mind) is the total sphere of the human intellect, that according to Eugene P. Odum (Basic Ecology, Saunders, Philadelphia etc., 1983, page 53) is 'gradually replacing the biosphere, the naturally evolving world, which has existed for [thousands of millions] of years.' The noosphere thus includes the 'sociosphere', which we may characterize as the system of installations, capabilities, and other non-structures, that Mankind has acquired or devised in developing both the internal relationships of human society and the wider relationships between that society and both The Biosphere and the built etc. 'technosphere'. The noosphere thus includes the totality of socio-political, socio-economic, and sociocultural, institutions and capabilities, that prevail in and around human society. To the extent that it includes the sociosphere, it is a Man-engendered system that has evolved through many centuries of human history, hence combining components which date from an earlier past with perforce more modern and particularly contemporary institutions, arrangements, and capabilities. These include political thrusts and legislations to carry out agreed actions which, given the basic understanding and global willpower to conform to the edicts of science, could well save our world and herald for it an era of equable sustainability.

The difficulty, of course, lies in persuading people to heed at all widely those edicts of science, which some of us have been trying to propagate for more than two decades. And yet if we think of the differences between the middle 1960 s and now, when practically every responsible government has to have its environmental ministry and practically everybody has heard of the greenhouse effect, the stratospheric ozone shield, and the dangers of devegetation and apparently concomitant climatic and sea-level changes, the advances in public realization and action are impressive - to the extent that further advances might still suffice to save The Biosphere as our one-and-only life-support. But will they be in time? That is a question the answer to which only the future will reveal.

Two points clamour for attention here, one being that we humans are all selfish to some extent, being commonly far more concerned about our own immediate surroundings and circumstances than about the rest of the world. The other point is that, in the ultimate analysis, it is the world as a whole which should matter-even to us; for whereas we cannot do without it, it can manage without us, and indeed did so very well for thousands of millions of years before our advent. Now it is we humans who are upsetting The Biosphere of which we nevertheless remain a part-often unwittingly but with atrocious effects until we learn to act together in ways that really matter, such as conserving irreplaceable raw materials.

So is it not possible that a kind of worldly holism - a Biospheral centricity or global biocentricity-may in time take the place of our present egocentricity? To judge by the speed with which the environmentalconservational movement took root and advanced as indicated above, there would seem to be at least a fair chance that due attention to the potentialities of the noosphere to save The Biosphere could be realized in time, and so we welcome the prospect of publishing in our next issue a paper currently entitled 'Our Key System: The Sociosphere' by a distinguished scientist-senator and your humble servant.

Nicholas POlunin 